\title{
PLANNING, SCHEDULING AND RESOURCE OPTIMISATION OF MULTIPLE PROJECTS USING ORACLE PRIMAVERA P6
}

\author{
Sushant Pradhan ${ }^{1}$, Rajendra ..$^{2}$, Vijay.K ${ }^{3}$ \\ ${ }^{I}$ P.G Student, Department of Civil Engineering, N.C.E.T, Visvesvaraya Technological University, Bangalore, India \\ ${ }^{2}$ Professor and Head (P.G), Department of Civil Engineering, N.C.E.T, Visvesvaraya Technological University, \\ Bangalore, India \\ ${ }^{3}$ Associate Professor, Department of Civil Engineering, N.C.E.T, Visvesvaraya Technological University, Bangalore, \\ India
}

\begin{abstract}
The construction industry today has bloomed by leaps and bounds. Every construction industry face a stiff competition in every section of project, be it technique, equipment, methodology or management. The goals are been created and the benchmark is getting higher. Construction Industries involve themselves in numerous projects and also aim for higher turnover as financial benefit is the ground reality. The task becomes tougher when one indulges to maintain customer satisfaction i.e. quality and duration at the same time. Seldom have the companies failed to attend the promise. Hence, the solution is "better project management". Companies in the past have faced a lot of problems especially when it comes to "multiple projects". The data are overloaded, the cost has been overrun, the duration is extended and the resources have been over-allocated. Thus resulting in improper project management. Hence this study of mine would like to serve as a reference while managing such kind of multiple projects. There are three sites considered and the work is been done simultaneously. The software used is Oracle Primavera P6.
\end{abstract}

Keywords: Planning, Scheduling, Resource optimization, Multiple Projects, Oracle Primavera P6

\section{INTRODUCTION}

Civil Engineering has been creating a transition in the developing phase of the world for centuries. The construction industry has become very vast and project management has been a matter of keen importance. Any Civil Engineering Project starts with an idea to meet the necessity of the citizen; it later gets transformed to a physical realization.

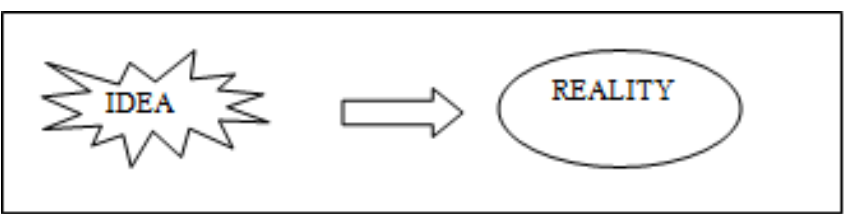

Fig 1:- The beginning and end of a Civil Engineering Project

Today in India the construction industry has been doing quite well and has become popular. For a developing country like India construction industry is the base for development. It also provides employment on a large scale. The size, situation and purpose for construction projects vary accordingly. To enhance a proper outcome they have been practicing Project management. Construction industry is a combination of manufacturing industry and services industry. In the manufacturing industry the process is been valued whereas in service industry the person handling the process is been valued. Though construction industry is comprised more of service industry the complementary cannot be ignored. The construction industry spends very little on research and development as to maintain confidentiality of the methods used. The key to customer satisfaction are budget, time and quality. The project manager needs to maintain trade-off between them also coordinating proper planning, design and management. Securing such task needs proper management. On the contrary these are the challenges faced by any construction industry. To maintain their balance proper planning, scheduling and monitoring is required with a proper document handling system. There will be numerous activities with different resources and updating them manually would be difficult. On top of that a company may be handling numerous projects at a time at different places. So with this new involvement of management and technology it has been co-operative in acquiring proper results. In case of multiple project management by a project manager the task becomes more difficult. The constraints vary in different sites and managing them within safe limits is a daily challenge.

\subsection{Planning}

It is the process of retrieving an organization's aim and generating a pragmatic, comprehensive plan of execution for the future project phases. In construction industry a project manager takes sole responsibility for maintaining cost, time and quality. Usually a construction industry lacks proper planning and hence ends up in bearing high cost, delay in time and low quality work. The only solution for is to follow a proper management system for planning. In some cases a project manager will be handling multiple projects and planning needs to be done properly especially for the allocation of resources. 


\subsection{Scheduling}

It is the process of arranging a project's milestones, activities and outputs within a specified time. Every construction project has a start and a finish date. There will be a lot of activities to perform an event. Scheduling those activities in an efficient way can trigger better deliverables. The main intention in scheduling is to maintain a proper sequence of activity flow. One should not create a confusion in the activity by creating an improper sequence e.g.:- the foundation work should be completed before the superstructure starts. Here, there is no other possibility of starting the construction of the superstructure before the completion of the substructure. But one could start with the storing of raw materials at site to prevent delay at later stages. In case of multiple projects the project manager should be aware of all the scenario in different project sites. If any constraints are present then he should solve them tactfully.

\subsection{Resource Optimisation}

Every construction project needs man, material and money. These are the basic requirement to start any construction project. Along with them we also need machines and method to complete a task. These are the resources needed while commencing a project and during execution. The word optimization means to make the maximum possible positive use of an input. So, resource optimization is to use these available resources in a most efficient way to achieve maximum efficiency. For instance in a construction industry while allocating bricks of concrete blocks for a wall, the proper number should be estimated rather than simply moving on with thumb rule. For an excavation to be done it can be done both manually and mechanically but the cost in both the cases vary. Here, it depends on the project managers preference over the constraints which may be time or cost. In multiple projects resource allocation becomes more tedious. If the resources are a site constraint then the execution work would be hampered accordingly.

\subsection{Multiple Projects}

Every enterprise in the construction industry is facing stiffness in completion as everybody is aiming for an ace. To become the number one these companies get involved in numerous projects according to their potential. There are various categories of work field inside a company e.g.:buildings, roads, power, bridges etc. Apparently there are different project managers handling each category and within each category there may be different projects working simultaneously. The management should be well aware of the activities and the resources needed in its occurrence in all the multiple projects.

\section{LITERATURE REVIEW}

Young Hoon Kwak and Frank T Anbari (2008) have analyzed Project Management Research referring the top management journals and have enlightened us with their perspective. There has always been a skeptical answer to decide whether project management is a "practice" or "an academic principle". The study of origin, history and evolution of project management is vivid and hence the research programs face limitations when tried to convey the answer for a broader academic audience. In their research paper they have reviewed the best journals in management from the Institute for Operations Research and Management Sciences (INFORM) , Academy of Management (AOM) and Institute of Electrical and Electronic Engineer (IEEE). The paper was a review of journals accounting for more than 50 years. The writers wanted to achieve and create a better understanding of the evolution of project management as a platform of practice and academic discipline and also help the succession scholars for more information regarding project management. They also suggested a list of the most least mentioned subjects according to their ranks over the past half a century were i) Strategy/Portfolio Management, ii) Operation Research/ Decision Sciences, iii) Organisation Behaviour/ Human resource Management, iv) Information Technology/ Information System, v) Technology Application/ Innovation, vi) Performance Management/Earned Value Management, vii) Engineering/Construction and viii) Quality Management/Six Sigma. With their analysis there was an upward trend of $30 \%$ of project management in future.

Yong-Cheol Yang, Chan-Jung Park, Ju-Hyung Kim and Jae-Jim Kim (2007) in the paper "Management of Daily Progress in a Construction Project of Multiple Apartment Buildings" have mentioned about managing the daily progress in multiple apartment buildings in South Korea. It is a case study of the used Project Management System for 54 apartments. Maintaining documents of cost and material handling for 54 parallel projects would obviously cause a stress in the management. They have used Cost Breakdown Structure and Work Breakdown Structure for this system. Along with that they have also used Budgeted Cost of Work Schedule, Budgeted Cost of Work Performed, Actual Cost of Work Performed, and Budget at Completion and Estimate at Completion for decision making criteria for variance in scheduling of project and cost endurance. MS-EXCEL Bar Charts were used for scheduling. They have allocated the budget instead of resources to activities so that they could keep an update of the daily progress. The system was applied to the multiple apartment project and could give satisfactory feedback.

Sharyar Wani, Mutasim Elsadig Adam, Husein Osman Abdullahi, Jamludin Bin Ibrahim (2012) have discussed about the problems faced by project managers while handling Parallel Projects. The aim of the paper reveals the impact of parallel project on one another and effects on project schedule, budget and the quality. They have conducted the survey by distributing project management related questionnaires to project managers from International Islamic University Malaysia. They have conducted interviews with project managers having experience in handling multiple projects. The interviews were mostly face to face and to get relevant and proper answers for the questions. All the questions were related to challenges and options of handling multiple projects in 
terms of cost, time and quality. From all the above mentioned methodology they concluded that the basic problem faced by project managers were cost overrun, delay and low quality work. Also in some cases the co-ordination between projects does not match.

Rong-yau Huang and Kuo-Shun Sun (2006) have done a case study on Non-Unit Based Planning and Scheduling of Repetitive Construction Projects. They have performed a case study of a sewer system project and have discussed their views over it. They have considered repetitive activity groups rather than repetitive units for their approach which sounds rational and effective. The writers have focused on similar activities which may have different cost, time, construction conditions and resource usage. They have engaged labor resource as per the requirement to complete the activity rather than allotting them according to their skill as in traditional methods. So, here now it becomes compulsory for them to take a note of the time taken to complete each activity. They have performed it by maintaining proper sequence of activities, cost and time while assigning multiple crews for an activity. Finally they have concluded by conveying a non-unit based algorithm. This could be useful in case of planning and scheduling of repetitive project.

Unmesh.Y.Polekar and Rohit.R.Salgude (2015) have analysed Planning, Scheduling and Tracking of a residential building using Primavera Software. The basic problem encountered while executing a project is a rise in cost and extension in the completion time. This could be solved with the help of proper management. The writers have thus suggested a better way for completing the project by planning, scheduling, and tracking the project using the primavera software. The study reveals the defects in planning and scheduling of activities. A comparison is done with the scheduled and actual progress of work. The importance of contractors in project has also been highlighted. Monitoring the project using the software proved to be more effective.

\section{CHALlenges IN MULTIPLE PROJECT}

\section{MANAGEMENT}

The challenges in managing multiple project are:-

- Project Duration - the project duration tends to lag while managing things at multiple sites.

- Interdependency of resources- since a single a company will be handling all the projects. The interdependency with activities and resources should be well understood.

- Scheduling of activities- to avoid any obstruction in delay of activity the scheduling should be in order throughout the project cycle.

- Project cost overrun- unfortunately sometime despite of utter care and precaution the cost moves up.

Handling constraints in each site respectively- every site will have its own constraint. These constraints should be dealt properly in time of planning and execution.

\section{RESOURCE OPTIMIZATION IN MULTIPLE PROJECTS}

Resources are non-other than the inputs while performing a work. They are an integral part of a project. To create any product or an element in case of construction industry the resources need to be integrated. In most of the site scenario the resources are limited. So, optimization needs to be done to get the maximum output. We can term them as Man, Material, Money and Machine. Each of them is equally important for proper development of planned task. They are often termed as $4 \mathrm{M}$ of management. All of them are calculated as per their requirement. We can understand them as follows:-

- Man: - in a construction industry "man" means engineers, skilled and unskilled labors in every human form needed to complete a given task. All of them are allotted according to their capacity of doing specified work. They have standard rates and are paid accordingly.

- Material: - it includes all the raw material needed for construction of a project. It may be cement, sand, coarse aggregates, steel, masonry items, flooring and finishing items. All the material resources are calculated before the plan is been executed.

- Machine: - machinery is also a resource as with the advancement of technology they have made our work easier and faster. Like other forms of resources machinery also comes with a price. They can charge us per hour of work or can be owned by the company itself, and then the operation charges come into light. Excavators, cranes, lift machines; generators are some type of machinery used on site.

- Money: - the most important of all is "money". It defines the budget of the whole project. All other resources are depended on it. It has the dominance to alter all other form of resources. For every project a specific amount is been allotted for all resources. Thus more the money betters the resource procurement.

\section{METHODOLOGY OF THE STUDY}

The methodology for my study started with the site exposure and data collection from the respective sites. Before executing in the software the list of activities, the duration for each activity, the resources required and organization workflow was studied as in the software all these would be integrated. The workflow of my study is shown in the figure given below:-

DATA COLLECTION AND VERIFICATION

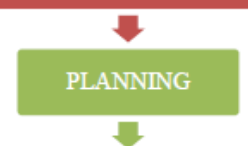

SCHEDULING

$\checkmark$

RESOURCE ALLOCATION

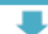

RESOURCE OPTIMISATION

Fig 2:- Flowchart of Methodology for a Single Project 
Since I have multiple projects under the same company the same process has to be followed for all the three projects and the resources have to be optimized. The Fig 3 shown below represents multiple projects.

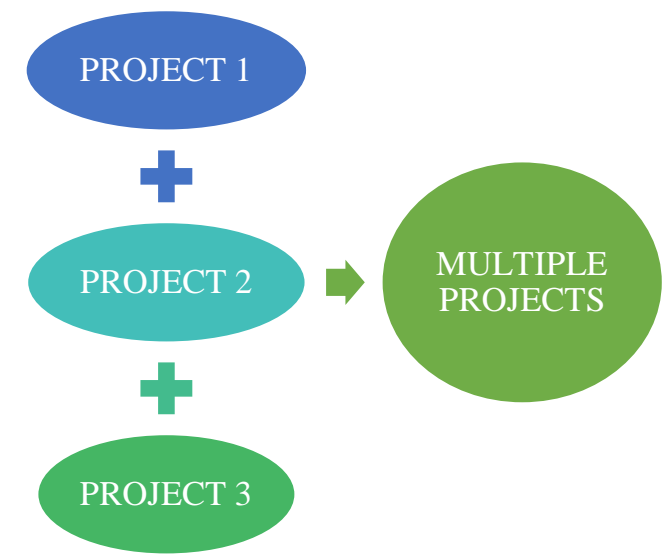

Fig 3:- Multiple Project Representation

\subsection{Data Collection}

The data provided by the company were:-

$>$ Drawings of Project 1

$>$ Drawings of Project 2

$>$ Drawings of Project 3

$>$ Quantity Survey of Project 1

$>$ Quantity Survey of Project 2

$>$ Quantity Survey of Project 3

\subsection{Planning}

After the collection of data and verifying the quantities planning for the project needed to be done. Among the three projects Project 1 and Project 2 had to be started on the same start date. A list to remember while planning for my study:-

$>$ The study involves three construction at different work site.

$>$ The biggest of all is Project I.

$>$ The second project size wise is Project II.

$>$ Now these two construction has to progress simultaneously and has the same start date.

$>$ Project II is followed by the Project III.

$>$ So halfway when Project I is completed Project II ends and then for the other half completion of Project I, Project II works simultaneously.

$>$ No two major activities should coincide in the simultaneous project.

$>$ The resources especially the labour resources are not abundant.

\subsection{Scheduling}

The scheduling process in my study had to be done while keeping in mind the concept of multiple project management. It includes creating calendars, work breakdown structures and allotting duration for activities. The calendar in my project has:-
$>9$ hours of working per day, from 8 a.m to $6 \mathrm{p} . \mathrm{m}$ with one hour lunch break

$>$ Sunday is also a working day of 5 hours

$>$ Holidays are less, so only Republic day, Labors Day and Independence Day is considered as holidays.

There are no exceptions considered while planning, the calendar is strictly according to the norms of the company.

\subsection{Resource Allocation}

After scheduling the activities the resource sheet is prepared and they are allocated in each activity. The resources in the software is divided into labor, non-labor and material. A sample of the method for calculating the resource is given below

\section{$>\quad$ Concrete:-}

For every $3 \mathrm{~m}^{3}$ of concrete 1skilled and 2 unskilled labor is required so now if the concrete quantity is $10 \mathrm{~m}^{3}$ and the allotted days is 2 , then the total quantity is divided by the number of days so,

$$
10 / 2=5 m^{3} \text { per day }
$$

But 1 skilled and 2 unskilled labors can do only $3 \mathrm{~m}^{3}$ of work per day, Now, we divide work to be done per day by the work done by 1 skilled and 2 unskilled labours;

$$
5 / 3=1.67 \text { number of labor, }
$$

Since we cannot have .67 labors we can consider it as 2 , if it was less than .50 we could have considered it as 1 . So the above calculations say that we need 2 skilled and 4 unskilled labors to complete the given job. Similarly for each and every item there are similar rules for work which can be divided according to work type and the labor resources can be estimated. With every addition of floor the unskilled labor has to be increased by one. The thumb rule is for every $3 \mathrm{~m}$ height 1 unskilled labor is added.

\subsection{Resource Optimization}

Practically we cannot level all the resources as it is not feasible and practically applicable. With all the site conditions the material resource cannot be optimized or reduced as the quantity for certain amount of work cannot be changed. While leveling resources there are various probabilities in which one can optimize the resource. The different type of probability used for my project while leveling the resource are:-

$>$ Level all resources with preserving scheduled early and late dates.

$>$ Level all resources within float preserving scheduled early and late dates.

$>$ Level particular resources preserving scheduled early and late dates.

$>$ Level particular resource within float preserving scheduled early and late dates.

$>$ Level particular resource without preserving scheduled early and late date. 
Since Mason, Masdoor and Coolie are the three labor resources which were used throughout all the three projects I chose them to optimize. All the probabilities were applied on the master project to get the best result. A comparison was made among them and the best can be chosen according to the site comfort ability.

\section{RESULTS}

The results of various methods used for the study are as follows:-

\section{Method 1}

Table -1: Results of Method 1

\begin{tabular}{|l|l|l|l|l|}
\hline $\begin{array}{l}\text { Name of } \\
\text { project }\end{array}$ & $\begin{array}{l}\text { Original } \\
\text { Duration } \\
\text { (days) }\end{array}$ & $\begin{array}{l}\text { Leveled } \\
\text { Duration } \\
\text { (days) }\end{array}$ & $\begin{array}{l}\text { Start } \\
\text { date }\end{array}$ & End date \\
\hline $\begin{array}{l}\text { Total } \\
\text { project }\end{array}$ & 300 & 314 & $1 / 1 / 16$ & $28 / 11 / 16$ \\
\hline Project I & 302 & 312 & $1 / 1 / 16$ & $28 / 11 / 16$ \\
\hline Project II & 157 & 175 & $1 / 1 / 16$ & $7 / 7 / 16$ \\
\hline Project III & 108 & 268 & $19 / 2 / 16$ & $3 / 7 / 16$ \\
\hline
\end{tabular}

\section{Method 2}

Table -2: Results of Method 2

\begin{tabular}{|l|l|l|l|l|}
\hline $\begin{array}{l}\text { Name of } \\
\text { project }\end{array}$ & $\begin{array}{l}\text { Original } \\
\text { Duration } \\
\text { (days) }\end{array}$ & $\begin{array}{l}\text { Leveled } \\
\text { Duration } \\
\text { (days) }\end{array}$ & $\begin{array}{l}\text { Start } \\
\text { date }\end{array}$ & $\begin{array}{l}\text { End } \\
\text { date }\end{array}$ \\
\hline $\begin{array}{l}\text { Total } \\
\text { project }\end{array}$ & 300 & 300 & $25 / 8 / 15$ & $11 / 7 / 16$ \\
\hline Project I & 302 & 302 & $25 / 8 / 15$ & $11 / 7 / 16$ \\
\hline Project II & 157 & 196 & $25 / 8 / 15$ & $22 / 3 / 16$ \\
\hline Project III & 108 & 300 & $25 / 8 / 15$ & $11 / 7 / 16$ \\
\hline
\end{tabular}

\section{Method 3}

Table -3: Results of Method 3

\begin{tabular}{|l|l|l|l|l|}
\hline $\begin{array}{l}\text { Name of } \\
\text { project }\end{array}$ & $\begin{array}{l}\text { Original } \\
\text { Duration } \\
\text { (days) }\end{array}$ & $\begin{array}{l}\text { Leveled } \\
\text { Duration } \\
\text { (days) }\end{array}$ & $\begin{array}{l}\text { Start } \\
\text { date }\end{array}$ & End date \\
\hline $\begin{array}{l}\text { Total } \\
\text { project }\end{array}$ & 300 & 316 & $1 / 1 / 16$ & $5 / 12 / 16$ \\
\hline Project I & 302 & 302 & $1 / 1 / 16$ & $17 / 11 / 16$ \\
\hline Project II & 157 & 201 & $1 / 1 / 16$ & $4 / 8 / 16$ \\
\hline Project III & 108 & 307 & $9 / 1 / 16$ & $5 / 12 / 16$ \\
\hline
\end{tabular}

\section{Method 4}

Table -4: Results of Method 4

\begin{tabular}{|l|l|l|l|l|}
\hline $\begin{array}{l}\text { Name of } \\
\text { project }\end{array}$ & $\begin{array}{l}\text { Original } \\
\text { Duration } \\
\text { (days) }\end{array}$ & $\begin{array}{l}\text { Leveled } \\
\text { Duration } \\
\text { (days) }\end{array}$ & $\begin{array}{l}\text { Start } \\
\text { date }\end{array}$ & $\begin{array}{l}\text { End } \\
\text { date }\end{array}$ \\
\hline $\begin{array}{l}\text { Total } \\
\text { project }\end{array}$ & 300 & 300 & $25 / 8 / 15$ & $11 / 7 / 16$ \\
\hline Project I & 302 & 302 & $25 / 8 / 15$ & $11 / 7 / 16$ \\
\hline Project II & 157 & 176 & $25 / 8 / 15$ & $29 / 2 / 16$ \\
\hline Project III & 108 & 127 & $10 / 2 / 16$ & $25 / 6 / 16$ \\
\hline
\end{tabular}

\section{Method 5}

Table -5: Results of Method 5

\begin{tabular}{|l|l|l|l|l|}
\hline $\begin{array}{l}\text { Name of } \\
\text { project }\end{array}$ & $\begin{array}{l}\text { Original } \\
\text { Duration } \\
\text { (days) }\end{array}$ & $\begin{array}{l}\text { Leveled } \\
\text { Duration } \\
\text { (days) }\end{array}$ & $\begin{array}{l}\text { Start } \\
\text { date }\end{array}$ & End date \\
\hline $\begin{array}{l}\text { Total } \\
\text { project }\end{array}$ & 300 & 316 & $1 / 1 / 16$ & $5 / 12 / 16$ \\
\hline Project I & 302 & 302 & $1 / 1 / 11$ & $17 / 11 / 16$ \\
\hline Project II & 157 & 201 & $1 / 1 / 16$ & $4 / 8 / 16$ \\
\hline $\begin{array}{l}\text { Project } \\
\text { III }\end{array}$ & 108 & 307 & $9 / 1 / 16$ & $5 / 12 / 16$ \\
\hline
\end{tabular}

There are numerous probabilities of optimizing resources of which we chose a few of the above. According to my companies requirement we had to chose the $3^{\text {rd }}$ and the $5^{\text {th }}$ method. The answers were also the same.

Advantages of the above method of resource optimization:-

$>$ The project cost remains same after leveling

$>$ There were no over allocations remaining which would incur in excess amount of expense while assigning additional labors.

> Practically it is not possible to order labors only for the over allocated days as labor resources are not easily available.

$>$ As compared to other methods, the chosen resources are getting optimized.

$>$ The requirement of the company is getting fulfilled; this would always be an advantage for the planner.

$>$ Customer satisfaction is reached.

\section{CONCLUSION}

Planning and scheduling helps in future reference and execution of the project. A well planned project suffers less amount of loss of time and cost. It is not possible to optimize all the resources; we should try to optimize them to a level up to which the company can execute the activities without much hindrance. The Primavera Software provides user friendly options while performing any task. The cost of individual work break down can be known along with the duration. The milestones for project such as slab and beam concreting which is one of the biggest activities can be forecasted earlier. Thus decisions can be made wisely for proper management. For finishing works there is always more amount of additional labor needed, thus scheduling them properly gives us an option to maintain proper procurement of resources. In multiple projects resource leveling is very important to maintain proper resource distribution. For multiple projects under a single company such analysis should be done to check out for over allocation. Scheduling simultaneous projects is also an important criterion for managing multiple projects. The similar types of activities should not coincide and must be avoided. If unavoidable then proper solutions should be provided to avoid delay.

\section{ACKNOWLEDGEMENT}

The study could not have been completed without the aid and assistance of our dear Principal. We would like to thank 
him for all his effort in guiding us. We would like to thank all the authors of various journals and books for enlightening us with their knowledge. We are grateful to our family, friends and the Department of Civil Engineering.

\section{REFERENCES}

[1]. Estimation and Costing in Civil Engineering by B.N Dutta, UBS Publishers Distributors Pvt Ltd (UBSPD).

[2]. Unmesh.Y. Polekar and Rohit. R. Salgude on "Planning, Scheduling and Tracking of a residential Project using Primavera Software". Volume 3, Issue 5, May 2015 International Journal of Advance Research in Computer Science and Management Studies.

[3]. Rong-yau Huang and Kuo-Shun Sun on "Non-UnitBased Planning and Scheduling of Repetitive Construction Projects". Journal of Construction Engineering and Management, ASCE , June 2006

[4]. SharyarWani, MutasimElsadig Adam, Husein Osman Abdullahi, and Jamaludin Bin Ibrahim on "Impact of Parallel Projects Management".International Journal of Humanities and Social Science Vol. 2 No. 23; December 2012

[5]. Yong-Cheol Yang, Chan-Jung Park, Ju-Hyung Kim and Jae-Jun Kim on "Management of Daily Progress in a Construction Project of Multiple Apartment Buildings". Journal of Construction Engineering and Management, American Society of Civil Engineers March 2007.

[6]. Young HoonKwak, Frank T Anbari on "Analyzing Project Management Research: Perspective from top Management Journals". International Journal of Project Management 27 (2009) 435-446. 